\title{
O LÚDICO E O ENSINO DE CIÊNCIAS: REFLEXÕES SOBRE A GINCANA “COMPARTILHANDO O CONHECIMENTO” NO ÂMBITO DO PROGRAMA RESIDÊNCIA PEDAGÓGICA
}

\author{
PLAY AND SCIENCE TEACHING: REFLECTIONS ON THE GINCANA \\ "SHARING KNOWLEDGE" IN THE FRAMEWORK OF THE PEDAGOGICAL \\ RESIDENCE PROGRAM
}

\author{
Vanusia Costa Ferreira ${ }^{1}$ \\ Antônia Vilma Matias de Sousa² \\ Leudimar do Nascimento Viana ${ }^{3}$ \\ Elson Silva de Sousa ${ }^{4}$ \\ Jesuino da Silva Costa Martins ${ }^{5}$
}

\begin{abstract}
Resumo: Diante das dificuldades envolvidas no Ensino de Ciências e a necessidade de abordagens lúdicas para facilitar o processo de ensino e aprendizagem, este artigo apresenta de forma sucinta um relato de experiência vivenciada pelos pesquisadores durante a aplicação de uma gincana intitulada "compartilhando o conhecimento" realizada com alunos do $6^{\circ}$ ano do Ensino Fundamental da Unidade Integrada Manoel Campos Sousa no município de Bom Jesus das Selvas - MA. A proposta foi desempenhada no âmbito do Programa Residência Pedagógica em maio de 2019. Os resultados apontam para a eficácia da proposta e demonstram a importância do uso dessas ações para proporcionar aos discentes de forma prazerosa o desenvolvimento da socialização, além de habilidades cognitivas.
\end{abstract}

Palavras-chave: Ensino de Ciências; Lúdico; Ensino e Aprendizagem.

Abstract: Because the difficulties involved in Science Teaching and the need for playful approaches to facilitate the teaching and learning process, this article succinctly presents an account of the experience lived by researchers during the application of a contest called "sharing knowledge" carried out with 6thyear students of Elementary School at the Manoel Campos Sousa Integrated Unit in the municipality of Bom Jesus das Selvas - MA. The proposal was carried out within the scope of the Pedagogical Residency Program in May 2019. The results point to the effectiveness of the proposal and demonstrate the

\footnotetext{
${ }^{1}$ Graduanda Licenciatura em Biologia, Instituto Federal de Educação, Ciência e Tecnologia do Maranhão (IFMA), Buriticupu, Maranhão, Brasil. E -mail: vanusia.costa@acad.ifma.edu.br

${ }^{2}$ Graduanda Licenciatura em Biologia, Instituto Federal de Educação, Ciência e Tecnologia do Maranhão (IFMA), Buriticupu, Maranhão, Brasil. E -mail: vilma.matias@acad.ifma.edu.br

${ }^{3}$ Licenciada em Biologia, Universidade Estadual do Maranhão (UEMA). Professora da rede muninipal de Bom Jesus da Selvas, Bom Jesus da Selvas, Maranhão, Brasil. E-mail: leudimarviana2018@ gmail.com

${ }^{4}$ Doutorando em Educação em Ciências e Matemática, Rede Amazônica de Educação em Ciências e Matemática. Professor EBTT, Instituto Federal de Educação, Ciências e Tecnologia do Maranhão, (IFMA), Buriticupu, Maranhão, Brasil. E-mail: elson.silva@ifma.edu.br

${ }^{5}$ Mestre em Genética e Melhoramento, Universidade Federal do Piauí (UFPI). Professor EBTT, Instituto Federal de Educação, Ciências e Tecnologia do Maranhão (IFMA), Buriticupu, Maranhão, Brasil. E-mail: jesuino.martins@ifma.edu.br
} 
DOI:10.33238/ReBECEM.2020.v.4.n.3.25163

ISSN 2594-9179

importance of using these actions to provide students with pleasure in the development of socialization, in addition to cognitive skills.

Keywords: Science teaching; Playful; Teaching and Learning

\section{Introdução}

Um dos grandes desafios que perpassam a atividade docente em sua prática é a capacidade de despertar o interesse de seus alunos pelos conteúdos ministrados. É consenso na literatura que a participação dos discentes em abordagens práticas é responsável por melhorar a capacidade de assimilar informações em comparação com métodos tradicionais (SILVA, 2017).

Sendo assim, é necessário que a abordagem dos conteúdos seja realizada de forma que possibilite o desenvolvimento cognitivo dos alunos, de forma que o ambiente escolar se configure como espaço propício para a vivência de experiências significativas aos discentes (BALBINOT, 2005). A memorização de conceitos é uma prática comum relacionada ao Ensino de Ciências (VASCONCELOS; SOUTO, 2003). Corazza-Nunes et al. (2006) afirmam que tal situação propricia a existência de analfabetismo científico entre estudantes, isso é evidenciado em exames internacionais que apontam a precária situação do aprendizado no Brasil, baseado apenas na memorização de informações desconexas e irrelevantes ao aluno (KRASILCHIK, 2009).

O Ensino de Ciências é reflexo da sociedade que o cerca (KRASILCHIK, 2000). Diante dos desafios atuais, é necessário que o ensino seja capaz de tornar o discente um cidadão crítico e reflexivo, de forma que possa ser capaz de utilizar os conteúdos na resolução dos seus problemas. O discente deve possuir o protagonismo do seu aprendizado.

O Ensino de Ciências deve proporcionar aos discentes a capacidade de interpretar e avaliar as informações veiculadas em diversos meios, além de argumentar e participar efetivamente da solução de problemas e ajudar na qualidade de vida dos seres vivos em geral (OLIVEIRA, 2010), além de permitir a compreensão do ambiente natural e social que o cerca (BRASIL, 1996).

É notório as dificuldades em ensinar Ciências (LIMA et al., 2016). Sendo assim, faz-se necessário que o professor ao longo de sua prática docente utilize diversas estratégias metodológicas para mediar a aprendizagem de conteúdos dessa área de conhecimento (BARTZIK; ZANDER, 2016). 
DOI:10.33238/ReBECEM.2020.v.4.n.3.25163

Nesse contexto, destaca-se o uso de atividades práticas que consistem na interação entre o aluno e o conteúdo. Esse tipo de atividade deve ser utilizada nas aulas de Ciências, proporcionando aos discentes uma aprendizagem mais eficaz dos conteúdos teóricos trabalhados em sala, estabelecendo dessa forma o diálogo entre teoria e prática. Segundo Andrade e Massabni (2011), essas atividades permitem que o aluno adquira conhecimentos que vão além da simples transmissão de conteúdo das aulas expositivas, sendo compromisso do professor, juntamente com a escola, oferecer essa oportunidade para a formação do aluno.

Nesse cenário o lúdico apresenta-se como uma possibilidade de ressignificação da abordagem didática. Apesar de sua existência antiga na sociedade (HUIZINGA, 2008), nos últimos anos seu uso no processo educacional vem sendo recorrente em diferentes práticas de ensino (ANJOS; MARTINS; FORTUNA, 2018). Essa conotação deve ser envolvida de aspectos pedagógicos para que o "brincar", não seja considerado pejorativo e sim uma temática carregada de significação para o contexto escolar (SANTOS, 2001).

A essência de brincar cria uma relação entre situações pensadas e reais, sendo importante fator do desenvolvimento cognitivo (SILVA; METTRAU, BARRETO, 2008). Esse recurso possibilita o desenvolvimento de habilidades cognitivas ao trabalhar a capacidade de resolução de problemas, além de facilitar a apropriação de conceitos pelos discentes (CAMPOS; BORTOLOTO; FELÍCIO, 2003).

A ludicidade é responsável por potencializar formas de pensar, diferenciar, interpretar, formular e decifrar (CAMPOS et al., 2014). A aplicação de recursos lúdicos quando aplicados corretamente no âmbito escolar é responsável pela integração do conhecimento ao discente e corrobora para uma educação crítica e significativa (SILVA et al., 2019).

As atividades dinâmicas tornam a aprendizagem mais eficaz por torná-la mais divertida e espontânea ao envolver os discentes fisicamente e cognitivamente com as atividades, facilitando a aprendizagem de conteúdo. Dessa forma, entendemos que:

\footnotetext{
O jogo possibilita a aprendizagem do sujeito e o seu pleno desenvolvimento, já que conta com conteúdo do cotidiano, como as regras, as interações com objetos e a diversidade de linguagens envolvidas em suas práticas. Desse modo, com base no pressuposto de que a prática pedagógica possa proporcionar alegria aos alunos no processo de aprendizagem, o lúdico deve ser levado a sério na escola, proporcionando-se o aprender por meio do jogo e, logo, o aprender brincando. Podemos deduzir, assim, que a formação lúdica do professor favorece essa prática (RAU, 2011, p.30)
} 
DOI:10.33238/ReBECEM.2020.v.4.n.3.25163

Nessa mesma abordagem Antunes (2001) destaca o quanto os jogos podem ser valiosos ao envolver o interesse e promover expressivo progresso no desenvolvimento dos participantes. De forma complementar, destaca-se:

\begin{abstract}
Num contexto de jogos, a participação ativa do sujeito sobre o seu saber é valorizada por pelo menos dois motivos. Um deles deve-se ao fato de oferecer uma oportunidade para as crianças estabelecerem uma relação positiva com a aquisição do conhecimento, pois conhecer passa a ser percebido como uma real possibilidade. Crianças com dificuldades de aprendizagem vão gradativamente modificando a imagem negativa do ato de aprender, tendo uma experiência que aprender é uma atividade interessante e desafiadora. Por meio de atividades com jogos, as crianças vão ganhando autoconfiança e são incentivadas a questionar e corrigir suas ações, analisar e comparar pontos de vista, organizar e cuidar materiais utilizados (MACEDO; PETTY; PASSOS, 2000, p.24)
\end{abstract}

É nesse contexto que uma gincana permeada de atividades e jogos didáticos ganha espaço como instrumento motivador para a aprendizagem de conhecimentos científicos, na medida em que propõe estímulo ao interesse do estudante (GARCIA, 2010). A gincana intitulada "Compartilhando o conhecimento" foi desenvolvida no âmbito do Programa Residência Pedagógica lançado em 2018 pela Coordenação de Aperfeiçoamento de Pessoal de Nível Superior proposta pelo edital 6/2018, visando articular a teoria e a prática docente (CAPES, 2018). Considerando a importância do uso de atividades lúdicas que possam despertar o interesse discente, além de estimular professores a desenvolver tais atividades, este trabalho tem como objetivo relatar a experiência dos autores durante a aplicação de uma gincana em turmas do $6^{\circ}$ ano do Ensino Fundamental desenvolvida na Unidade Integrada Manoel Campos Sousa, município de Bom Jesus das Selvas- MA.

\title{
2 Percurso Metodológico
}

A execução da proposta envolveu diretamente professores e discentes do curso superior de licenciatura em Biologia do Instituto Federal do Maranhão, campus Buriticupu, participantes do Programa Residência Pedagógica (RP). Dessa forma, estabelece a pesquisa-ação como metodologia, em virtude da intervenção dos pesquisadores nas diferentes situações da gincana (SEVERINO, 2007). Esse artigo apresenta um relato qualitativo descritivo.

Em um primeiro momento foi realizado uma reunião com professores, gestores e pedagogos da Unidade Integrada Manoel Campos Sousa de forma a discutir os 
DOI:10.33238/ReBECEM.2020.v.4.n.3.25163

objetivos da Gincana. Em seguida, foram desenvolvidas as provas a serem inseridas na atividade, as escolhas foram baseadas nos conteúdos trabalhados em sala de aula no Componente Curricular de Ciências ao longo do primeiro semestre letivo do ano de 2019.

Todo material confeccionado e utilizado na gincana foi de baixo custo e de fácil confecção de modo a facilitar a acessibilidade e a produção do evento. As tarefas criadas que compuseram a gincana foram: a) Montagem da cadeia alimentar; b) Prova do Balão; c) Classificação dos seres vivos em uma cadeia alimentar; d) Prova dos cadeados; e) Estouro do balão. As atividades foram desenvolvidas no pátio e na quadra da escola, envolvendo quatro turmas do $6^{\circ}$ ano do Ensino Fundamental abrangendo um total de setenta e cinco alunos, sendo realizada em evento único no turno matutino em 10 de maio de 2019.

Os discentes foram divididos em três equipes, sendo diferenciadas por cores: $6^{\circ}$ ano $\mathrm{A}$ (vermelho); $6^{\circ}$ ano $\mathrm{B}$ (azul); $6^{\circ}$ ano $\mathrm{C}$ (verde). Cada equipe possuía os alunos residentes como responsáveis. A condução das provas foi realizada pela professora titular do Componente Curricular de Ciências.

Durante a primeira prova as imagens de diversos organismos vivos foram disponibilizadas para as equipes. Os participantes de cada turma possuíam o tempo de até 3 minutos para a montagem correta de uma cadeia alimentar completa com produtores, consumidores e decompositores. Ao final do tempo, os residentes contabilizavam os acertos para a pontuação geral. Na segunda prova foi realizada uma atividade lúdica de forma a aumentar a participação e o trabalho em grupo dos discentes, três alunos de cada equipe possuíam balões amarrados em suas pernas, vencia a prova o time que estourasse o maior número de balões da equipe adversária.

A terceira prova buscava relacionar o nome dos organismos com seu respectivo papel na cadeia alimentar de acordo com os nomes produtor, consumidor e decompositor. Os representantes de cada time deveriam associar as imagens apresentadas pelos residentes aos respectivos nichos ecológicos.

$\mathrm{Na}$ quarta prova os discentes deveriam responder a um conjunto de perguntas sobre ecologia. Cada resposta correta correspondia a uma chave que abria uma sequência de cadeados. A equipe vencedora nessa prova seria a que tivesse o maior número de respostas corretas. O mesmo tipo de atividade (perguntas - respostas), também foi utilizado na quinta e última prova, um aluno ficou sentado em uma cadeira e 


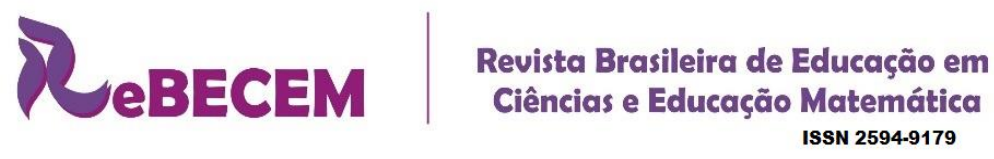

DOI:10.33238/ReBECEM.2020.v.4.n.3.25163

os demais pegavam balões cheios caso acertassem as perguntas feitas pela professora. A cada resposta correta o discente corria para estourar o balão na perna do aluno que estava sentado, a equipe que estourasse mais balões vencia a prova (Figura 1).

Ao final de cada prova realizada o grupo vencedor era anunciado. Ao final da gincana foi realizada uma confraternização que envolveu os discentes, residentes, professores e gestores da escola. A premiação foi distribuída posteriormente para a equipe vencedora.

Figura 1: Atividades da Gincana "Compartilhando Conhecimento" realizada na Unidade Integrada Manoel Campos Sousa, município de Bom Jesus das Selvas. A - Processo de planejamento entre residentes e professora. B- Jogo de Perguntas e respostas. C/D - Execução do jogo "montagem da cadeia

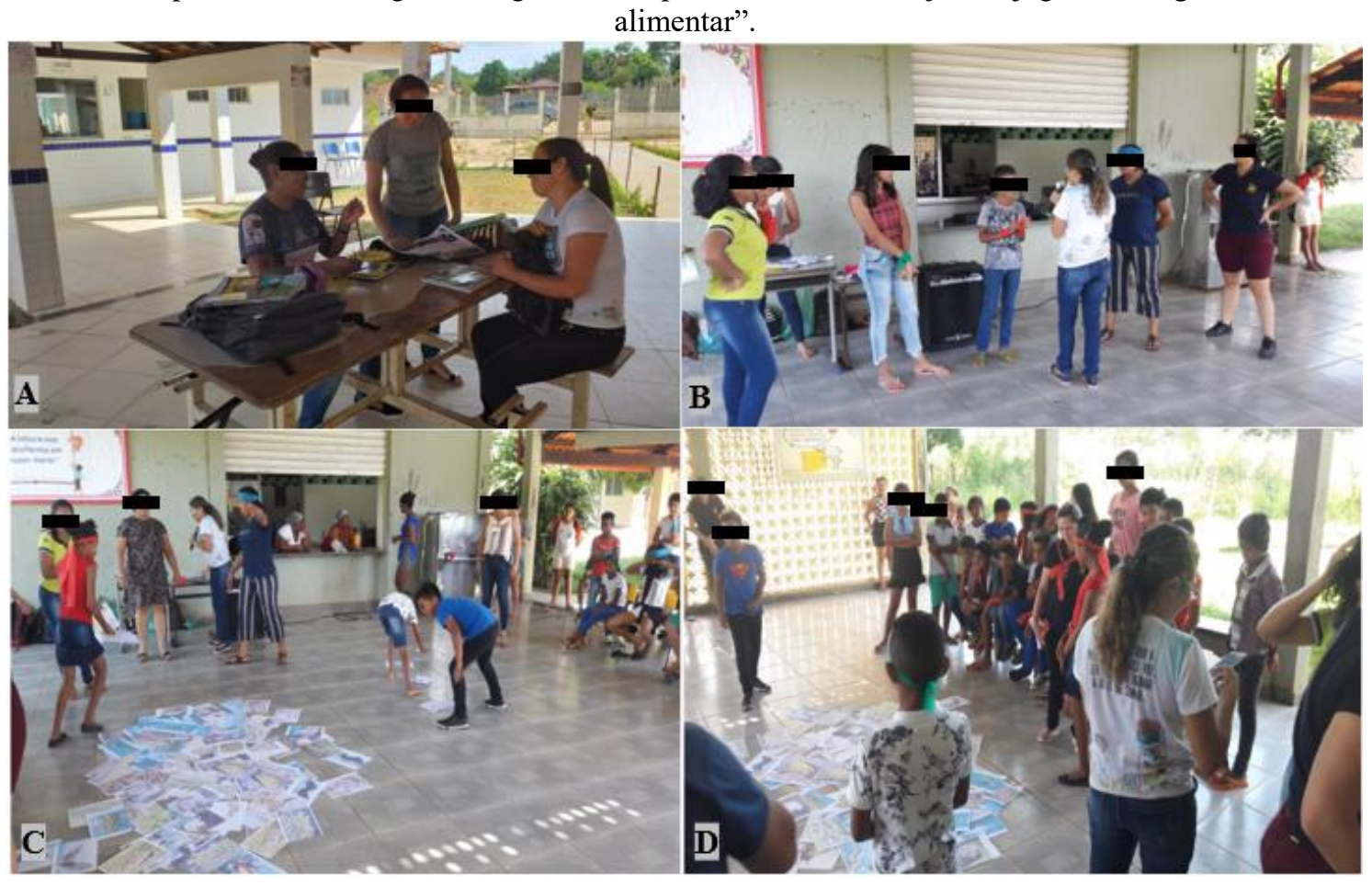

Fonte: Produção dos Autores

\section{Vivências}

Diante das novas concepções de ensinar, é cada vez mais comum que os professores utilizem metodologias que possibilitem a participação ativa dos discentes no processo de ensino e aprendizagem. Após a realização da gincana observamos relatos dos docentes da escola que os jogos desenvolvidos permitiram maior interatividade entre os discentes da turma atestando assim para a experiência positiva na participação das provas. Esse aspecto é de extrema relevância ao incentivar demais docentes a 
DOI:10.33238/ReBECEM.2020.v.4.n.3.25163

desenvolverem em outros componentes curriculares atividade lúdicas de forma a trabalhar questões interdisciplinares.

Nesse cenário o Programa Residência Pedagógica (CAPES, 2018) possibilitou aos professores em formação do curso de Licenciatura em Biologia do IFMA campus Buriticupu a possibilidade de imersão em uma realidade escolar de forma a refletir sobre o papel do professor no ensino de Ciências, oportunizando criar/aprender métodos de ensino que possam quebrar a dicotomia existente entre a teoria e a prática nos curso de formação (SAMPAIO; BARROS, 2015).

Com a aplicação da gincana constata-se que o uso de atividades lúdicas é um caminho auxiliar no processo de ensino e aprendizagem (SILVA, 2017). Aspectos positivos superaram as expectativas dos residentes, professores e gestores, o respeito entre as equipes e o cumprimento das regras estabelecidas demonstram a importância dessas ações no ambiente escolar.

Os dados obtidos na presente pesquisa estão de acordo com a literatura. As atividades lúdicas quando bem exploradas, oportunizam o respeito e a interlocução de saberes e a socialização dos indivíduos, além da valorização das normas e regras construídas (RIBEIRO et al., 2016). As gincanas escolares proporcionam diversos fatores significativos, sendo uma de suas principais funções despertar no aluno o interesse e a motivação pelos conteúdos de Ciências de maneira a facilitar a sua compreensão (SAMPAIO; BARROS, 2015).

Durante a execução das provas, foi notório o engajamento, motivação e interesse dos discentes. O papel do lúdico é importante para a aprendizagem, a vivência dessa experiência permite afirmar, assim como Silva et al. (2019), que o uso de gincanas traz para a sala de aula "movimento" e quebra paradigmas na educação. Essa ação é benéfica a todos os participantes. De acordo com Silva (2017), essas atividades são extremamente valiosas no processo de apropriação do conhecimento, pois permitem o desenvolvimento de competências no âmbito da comunicação, das relações interpessoais e do trabalho em equipe.

Apesar de não ter sido utilizado um método quantitativo para mensurar a aprendizagem, nota-se que as atividades lúdicas proporcionam o desenvolvimento cognitivo como podemos notar nas atividades e avaliações realizadas após a gincana. As questões respondidas de forma equivocada foram comentadas em sala de aula e durante as correções notou-se a participação dos alunos com a exposição de exemplos que não 
foram utilizados na gincana. Tal ação demonstra uma apropriação dos conteúdos ministrados. Dessa forma é necessário o planejamento adequado entre o lúdico e o pedagógico de forma a atingir os objetivos planejados (SQUIRE, 2015; SÁ et al., 2018). Um jogo pedagógico é aquele no qual os objetivos são planejados e selecionados com o intuito de promover o desenvolvimento de conhecimentos específicos (BAIOTTO; DELLA MÉA, 2009). O papel do professor é fundamental pois são a sua presença e direcionamento que farão com que essa ação pedagógica seja afirmada e efetivada (SILVA; MASSAROLI; BUTNARI, 2018).

\section{Considerações Finais}

Percebemos que a aplicação da gincana proporcionou maior dinamismo e interesse nas aulas de Ciências, além de ser uma importante atividade de formação para licenciandos e professores.

A mera memorização de conceitos e conteúdos deve ser combatida. Para tanto, a utilização de gincanas pedagógicas e outras metodologias didáticas devem ser incentivadas no contexto educacional para estimular a participação dos discentes. Essas ferramentas são eficazes e aproxima os alunos do conhecimento científico.

A gincana "Compartilhando o Conhecimento" proporcionou aos alunos um momento de lazer educativo e oportunidade em aplicar o conhecimento sobre os conteúdos ministrados em sala de aula durante as atividades propostas, caracterizando assim, a importância de atividades lúdicas no desenvolvimento da aprendizagem. Os resultados indicam a eficácia ao utilizar-se do lúdico no processo de ensino e aprendizagem de Ciências, promovendo diversas habilidades como, a compreensão dos conteúdos, a argumentação e socialização.

\section{Referências}

ANDRADE, M. L. F.; MASSABNI, V. G. O desenvolvimento de atividades práticas na escola: um desafio para os professores de ciências. Ciência \& Educação, Bauru, v. 17, n. 4, p. 835$854,2011$.

ANJOS, S. R.; MARTINS, L.; FORTUNA, J. L. Jogos educativos elaborados em uma escola pública estadual. Revista Ciências e Ideias, Rio de Janeiro, v. 9, n. 2, p. 81-93, 2018. 
ANTUNES, C. Jogos para a estimulação das múltiplas inteligências. Petrópolis: Vozes, 2001.

BAIOTTO, C. R.; DELLA MÉA, A. R. A produção de jogos didáticos para o ensino de genética: uma proposta para favorecer a aprendizagem. Revista Universitária Cataventos, Cruz Alta, v.1, n.1, p. 34-40, 2009.

BALBINOT, M. C. Uso de modelos, numa perspectiva lúdica, no ensino de ciências. In: ENCONTRO IBERO-AMERICANO DE COLETIVOS ESCOLARES E REDES DE PROFESSORES QUE FAZEM INVESTIGAÇÃO NA SUA ESCOLA, iv, 2005, Lajeado. Anais...Lajeado (RS): Univates, 2005.

BARTZIK, F.; ZANDER, L. D. A Importância Das Aulas Práticas De Ciências No Ensino Fundamental. Revista @ rquivo Brasileiro de Educação, Belo horizonte, v.4, n. 8, p. 31-38, 2016.

BRASIL. Ministério da Educação. Lei número 9.394, 20 de dezembro de 1996. Lei de Diretrizes e Bases da Educação Nacional. Brasília, DF: Diário Oficial da União, 1996.

CAMPOS, D. B.; MELLO, R.; SILVA, M. C.; FAGUNDES, A. B.; PEREIRA, D.

Aprendizagem significativa com apelo ao lúdico no ensino de química orgânica: estudo de caso. Interscience Place, Campo dos Goytacazes, v. 1, n. 31, p. 241-267, 2014.

CAMPOS, L. M. L.; BORTOLOTO, T. M.; FELICIO, A. K. C. A produção de jogos didáticos para o ensino de Ciências e Biologia: uma proposta para favorecer a aprendizagem. Caderno dos Núcleos de Ensino, Pelotas, p.35-48, 2003.

CORAZZA-NUNES, M. J.; PEDRANCINI, V. D.; GALUCH, M. T. B.; MOREIRA, A. L. O. R.; RIBEIRO, A. C. Implicações da mediação docente no processo de ensino aprendizagem de biologia no ensino médio. Enseñanza de la Ciências, Vigo, v. 5, n. 3, p. 522-533, 2006.

Fundação CAPES. Programa de Residência Pedagógica. Edital Capes nº 6/2018 - Residência Pedagógica. 2018. Disponível em:

<http://www.capes.gov.br/images/stories/download/editais/01032018-Edital-6-2018Residenciapedagogica.pdf $>$. Acesso em: 24 de junho de 2019.

GARCIA, M. W. Jogo didático como estratégia complementar ao ensino de Botânica no Ensino Médio em uma escola particular de Barretos-SP. 2010. 99 f. Trabalho de Conclusão do Curso (Graduação em Ciências Biológicas e Saúde) - Universidade Presbiteriana Mackenzie, São Paulo, 2010.

HUIZINGA, J. Homo ludens: O jogo como elemento da cultura. Tradução João Paulo Monteiro. 5. ed. São Paulo: Perspectiva, 2008. 
KRASILCHIK, M. Biologia - ensino prático. In: CALDEIRA, A.M.A (Org.). Introdução à didática da biologia. São Paulo: Escrituras, 2009. p. 249-258.

KRASILCHIK, M. Reforma e Realidade: o caso do ensino de ciências. São Paulo em perspectiva, São Paulo, v. 14, n.1, p. 85-93, 2000.

LIMA, G. H.; SILVA, R.S.; ARANDAS, M.J.G.; LIMA, N.N.; CANDIDO, J.H.B.; SANTOS, K.R.P. O uso de atividades práticas no ensino de ciências em escolas públicas do município de Vitória de Santo Antão - PE. Rev. Ciênc. Ext., São Paulo, v.12, n.1, p.19-27, 2016.

MACEDO, L.; PETTY, A. L. S.; PASSOS, N. C. Aprender com jogos e situações problemas. Porto Alegre: Artmed, 2000.

OLIVEIRA, J.R.S. de. Contribuições e abordagens das atividades experimentais no ensino de ciências: reunindo elementos para a prática docente. Acta Scientiae, Canoas, v. 12, n. 1, p. 139$153,2010$.

RAU, M. C.T. D. A ludicidade na educação: uma atitude pedagógica. Curitiba: Ibpex, 2011.

RIBEIRO, M. H. S.; RAMOS, E. C. S. S.; CARVALHO, A. C.; CAVALCANTE, K. S. B.; BRANDÃO, C. M. Gincana "Química em velocidade máxima": ações do PIBID no Centro do Ensino Médio Gonçalves Dias em São Luís - MA. In: ENCONTRO NACIONAL DO ENSINO DE QUÍMICA, XVIII, 2016, Florianópolis. Anais... Florianópolis, UFSC: Sociedade Brasileira de Química, 2016.

SÁ, S. R. A.; CARDOSO, F. S.; MOTTA, E. S.; YAMASAKI, A. A. Jogo? Aula? "Jogo-aula": Uma estratégia para apropriação de conhecimentos a partir da pesquisa em grupo. Revista de Ensino de Biologia da SBEnBio, Santa Catarina, v.11, n. 2, p. 5-19, 2018.

SAMPAIO, J. S.; BARROS, J. S. O uso de gincanas pedagógicas para auxiliar o ensino aprendizagem. In: CONGRESSO NACIONAL DE EDUCAÇÃO, II, 2015, Campina Grande. Anais... Campinas Grande, PB: Conedu, 2015.

SANTOS, S M. P. dos. A Ludicidade como ciência. Petrópolis: Vozes, 2001.

SEVERINO, A. J. Metodologia do trabalho científico. $23^{\text {a }}$ ed. Cortez: São Paulo, 2007.

SILVA, A. M. T. B.; METTRAU, M. B.; BARRETO, M. S. L. O lúdico no processo de ensinoaprendizagem das ciências. Revista Brasileira de Estudos Pedagógicos, Brasília, v.88, n.220, 2008.

SILVA, F. O.; NAIMAN, W. N.; GONÇALVES, F. L. A.; LIMA, E. P. R.; ZAN, R. A.; BAPTISTA, J. A. A. Gincana de ciências da natureza: contribuições de atividades 


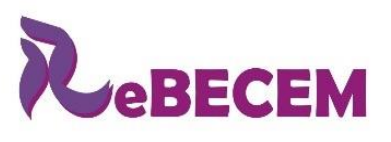

interdisciplinares lúdicas no processo de ensino-aprendizagem. Scientia Naturalis, Rio Branco, v. 1, n. 2, p. 183-193, 2019.

SILVA, L. A.; MASARROLI, A.; BUTNARI, A. R. Animal combate: um novo instrumento pedagógico para o ensino de ciências e biologia. Revista Educação em Perspectiva, Viçosa, v.8, n. 3, p. 496-517, 2018.

SILVA, T. R. O lúdico no ensino de Ciências da Natureza: Gincana Água e Energia. Revista Fluminense de Extensão Universitária, Rio de Janeiro, v.7, n. 1, p.3-7, 2017.

SQUIRE, K. Creating the Future of Games and Learning. Independent School, Washington, v. 74, n. 2, p. 2, 2015.

VASCONCELLOS, S. D.; SOUTO, E. O livro didático de ciências no ensino fundamental proposta de critérios para análise do conteúdo zoológico. Ciência \& Educação, Bauru, v. 9, n.1, p. 93-104,2003.

Recebido em: 5 de junho de 2020

Aceito em: 21 de julho de 2020 